\title{
Influence of pharmacogenetic variability on the pharmacokinetics and toxicity of the aurora kinase inhibitor danusertib
}

\author{
Neeltje Steeghs • Ron H. J. Mathijssen • Judith A. M. Wessels • Anne-Joy de Graan • \\ Tahar van der Straaten • Mariangela Mariani • Bernard Laffranchi • Silvia Comis • \\ Maja J. A. de Jonge • Hans Gelderblom • Henk-Jan Guchelaar
}

Received: 4 January 2010 / Accepted: 9 February 2010 / Published online: 25 February 2010

(C) The Author(s) 2010. This article is published with open access at Springerlink.com

\begin{abstract}
Summary Objectives Danusertib is a serine/threonine kinase inhibitor of multiple kinases, including aurora-A, $\mathrm{B}$, and $\mathrm{C}$. This explorative study aims to identify possible relationships between single nucleotide polymorphisms in genes coding for drug metabolizing enzymes and transporter proteins and clearance of danusertib, to clarify the interpatient variability in exposure. In addition, this study explores the relationship between target receptor polymorphisms and toxicity of danusertib. Methods For associations with clearance, 48 cancer patients treated in a phase I study were analyzed for $A B C B 1, A B C G 2$ and $F M O 3$ polymorphisms. Association analyses between neutropenia and drug target receptors, including KDR, RET, FLT3, FLT4, AURKB and $A U R K A$, were performed in 30 patients treated at recommended phase II dose-levels in three danusertib phase I or
\end{abstract}

\footnotetext{
N. Steeghs $\cdot$ H. Gelderblom $(\bowtie)$

Department of Clinical Oncology, K1-P,

Leiden University Medical Center,

P.O Box 9600, 2300 RC Leiden, The Netherlands

e-mail: A.J.Gelderblom@lumc.nl

R. H. J. Mathijssen - A.-J. de Graan • M. J. A. de Jonge Department of Medical Oncology,

Erasmus University Medical Center,

Rotterdam, The Netherlands

J. A. M. Wessels - T. van der Straaten · H.-J. Guchelaar Department of Clinical Pharmacy and Toxicology, Leiden University Medical Center,

Leiden, The Netherlands

M. Mariani $\cdot$ B. Laffranchi $\cdot$ S. Comis

Nerviano Medical Sciences,

Nerviano, Italy
}

phase II trials. Results No relationships between danusertib clearance and drug metabolizing enzymes and transporter protein polymorphisms were found. Only, for the one patient with $F M O 318281 \mathrm{AA}$ polymorphism, a significantly higher clearance was noticed, compared to patients carrying at least 1 wild type allele. No effect of target receptor genotypes or haplotypes on neutropenia was observed. Conclusions As we did not find any major correlations between pharmacogenetic variability in the studied enzymes and transporters and pharmacokinetics nor toxicity, it is unlikely that danusertib is highly susceptible for pharmacogenetic variation. Therefore, no dosing alterations of danusertib are expected in the future, based on the polymorphisms studied. However, the relationship between FMO3 polymorphisms and clearance of danusertib warrants further research, as we could study only a small group of patients.

Keywords Pharmacogenetics · Pharmacogenomics . PHA-739358 · Danusertib · Cancer: aurora kinase inhibitor

\section{Introduction}

Aurora kinases are serine/threonine kinases with a key role in mitosis [1-9]. Danusertib (PHA-739358) is a new active moiety in cancer treatment which selectively inhibits the ATP site of aurora-A (AURKA, $\mathrm{IC}_{50}=13 \mathrm{nM}$ ), aurora-B (AURKB, $\mathrm{IC}_{50}=79 \mathrm{nM}$ ) and aurora-C (AURKC, $\mathrm{IC}_{50}=$ $61 \mathrm{nM})$ kinases $[10,11]$. Inhibition of aurora-A or aurora-B activity in tumor cells results in impaired chromosome alignment, weakening of the mitotic checkpoint, polyploidy, and subsequent cell death [12,13]. Danusertib shows 
anti-tumor activity in a wide range of cancer cell lines and xenograft tumor models [14]. Tested in a panel of 32 kinases, danusertib also showed increased affinity for multiple other kinases $\left(\mathrm{IC}_{50}<0.50 \mu \mathrm{M}\right.$ ), including ret proto-oncogene (RET), vascular endothelial growth factor receptor 3 (FLT4, VEGFR3), and fms-related tyrosine kinase 3 (FLT3). Therefore, inhibition of these kinases may influence danusertib efficacy or toxicity in cancer patients.

The major route of metabolism of danusertib involves the formation of the N-oxide metabolite, mainly through the enzyme flavin containing monooxygenase 3 (FMO3), forming an inactive metabolite. Furthermore, danusertib was found to be a substrate for efflux proteins ATP-binding cassette $\mathrm{B} 1$ (ABCB1/MDR1) and G2 (ABCG2/BCRP in in vitro studies (unpublished data). In addition, it has been shown that histone $\mathrm{H} 3$ is phosphorylated by aurora-B and phosphorylation of histone $\mathrm{H} 3$ is inhibited in skin, bone marrow and xenograft tumors after treatment with danusertib [15]. As a consequence, the extent of histone H3 phosphorylation is studied as a pharmacodynamic biomarker of danusertib effectiveness.

Recently, this new compound has been introduced in human research. In a phase I study, performed at the Leiden University Medical Center, Leiden and the Erasmus University Medical Center, Rotterdam (The Netherlands), the pharmacokinetics of danusertib were characterized by relatively low to moderate plasma clearances (range 10-59 L/hour) and an elimination half-life of about $30 \mathrm{~h}$ [16]. Danusertib showed linear pharmacokinetics over the dose-range studied. At all dose levels, the inter-patient variability of the primary pharmacokinetic parameters of danusertib was remarkably high, with a coefficient of variation of $40-50 \%$, which is in line with other anti-cancer drugs. Toxicity increased with danusertib dose. However, currently it is unclear whether pharmacogenetic variability in drug metabolizing or transporting proteins can explain a large part of the inter-individual variability in pharmacokinetics and/or toxicity-profile. Therefore, the current explorative study aims to identify possible (and clinically relevant) relationships between single-nucleotide polymorphisms (SNPs) in genes coding for drug metabolizing enzymes and for transporter proteins and pharmacokinetic parameters of danusertib. In this study we also explore the possible relationship between polymorphisms in genes encoding the drug target receptors and toxicity of danusertib.

\section{Methods}

This study was conducted on patients treated with danusertib in 3 studies, one phase I and two phase II studies. Descriptions of the study population and treatment regimens are given in the patients and samples paragraph below.
Residual blood samples for pharmacogenetic analyses to compare with pharmacokinetics were available for all patients treated in the phase I study. For association analyses with toxicity, all patients treated at the recommended phase II dose (RP2D), in both the phase I and phase II studies, were included.

\section{Patients and samples}

Eligibility criteria, drug administration procedures, safety, pharmacokinetic and efficacy methods as used in the phase I trial are described in detail elsewhere [17].

Briefly, Group A patients had histologically or cytologically confirmed advanced or metastatic solid tumors for whom no standard therapy was available, with an Eastern Cooperative Oncology Group (ECOG) performance status $\leq 1$. Danusertib was administered intravenously on days 1 , 8,15 every 28 days. Doses were escalated from $45 \mathrm{mg} / \mathrm{m}^{2}$ to $400 \mathrm{mg} / \mathrm{m}^{2}$ in the 6-hour infusion schedule, and from $250 \mathrm{mg} / \mathrm{m}^{2}$ to $330 \mathrm{mg} / \mathrm{m}^{2}$ in the subsequent 3-hour infusion schedule. The trial had a standard $3+3$ phase I dose escalation study design. In the phase II study from which group B patients were entered, men with metastatic hormone refractory prostate cancer, progressive after docetaxel treatment were eligible. Patients of group B were randomized between treatment with $330 \mathrm{mg} / \mathrm{m}^{2}$ of danusertib on days $1,8,15$ every 28 days in a 6-hour infusion schedule or with $500 \mathrm{mg} / \mathrm{m}^{2}$ of danusertib on days 1 and 15 every 28 days in 24-hour infusion schedule according to the phase II study protocol. The total exposure in both groups is expected to be identical, and in line with the RP2D as determined in phase I studies $[8,18]$. For group $\mathrm{C}$, patients with several tumor types (see Table 1), progressive after 1 or 2 lines of chemotherapy depending on tumor type were eligible. Treatment consisted of $500 \mathrm{mg} / \mathrm{m}^{2}$ of danusertib on days 1 and 15 every 28 days in 24-hour infusion schedule. No pharmacokinetic analyses were performed in the phase II trials.

For all groups, patients were evaluated for adverse events and toxicity according to the National Cancer Institute Common Terminology Criteria (NCI-CTC), version 3.0. Response evaluation was performed every 2 cycles and was assessed according to RECIST 1.0 [19].

Residual blood samples taken for routine patient care were stored at $-20^{\circ} \mathrm{C}$ at the local hospital laboratories. Of each patient, one frozen whole blood sample was collected from the two participating hospitals. All samples were anonimyzed by a third party, according to the instructions stated in the Codes for Proper Use and Proper Conduct (www.federa.org). Approval from the institutional medical ethical review boards was obtained prior to analysis. 
Table 1 Patient characteristics, danusertib induced toxicity in the first cycle, and pharmacokinetic/pharmacodynamic results

\begin{tabular}{|c|c|c|c|}
\hline Baseline characteristics & All patients n $(\%) N=63$ & Phase I patientsn $(\%) N=48^{\mathrm{a}}$ & RP2D patients n (\%) $N=30^{\mathrm{b}}$ \\
\hline Gender, male & $43(68)$ & $35(73)$ & $20(67)$ \\
\hline Race, caucasian & $62(98)$ & $47(98)$ & $29(97)$ \\
\hline \multicolumn{4}{|l|}{ Age, years } \\
\hline Median (range) & $58(22-75)$ & $58(22-75)$ & $60(38-74)$ \\
\hline \multicolumn{4}{|l|}{ Patient Group } \\
\hline A (phase I) & $48(76)$ & $48(100)$ & $15(50)$ \\
\hline B (phase II, prostate cancer) & $7(11)$ & - & $7(23)$ \\
\hline C (phase II, various tumor types) & $8(13)$ & - & $8(27)$ \\
\hline \multicolumn{4}{|l|}{ RP2D Group } \\
\hline $330 \mathrm{mg} / \mathrm{m} 2 \mathrm{~d} 1,8,15$ every 4 weeks & $20(31)$ & $15(31)$ & $20(67)$ \\
\hline $500 \mathrm{mg} / \mathrm{m} 2 \mathrm{~d} 1$ and 15 every 4 weeks & $10(16)$ & - & $10(33)$ \\
\hline \multicolumn{4}{|l|}{ Tumor type } \\
\hline Colorectal cancer & $19(30)$ & $18(38)$ & $10(33)$ \\
\hline Breast cancer & $6(10)$ & $1(2)$ & $5(17)$ \\
\hline Esophageal cancer & $4(6)$ & $4(8)$ & $2(7)$ \\
\hline Ovarian cancer & $3(5)$ & $2(4)$ & $1(3)$ \\
\hline Pancreatic cancer & $4(6)$ & $3(6)$ & $1(3)$ \\
\hline Prostate cancer & $8(13)$ & $1(2)$ & $7(23)$ \\
\hline Miscellaneous & $19(30)$ & $19(39)$ & $4(13)$ \\
\hline \multicolumn{4}{|l|}{ ECOG performance score } \\
\hline 0 & $15(24)$ & $8(17)$ & $11(37)$ \\
\hline 1 & $48(76)$ & $40(83)$ & $19(63)$ \\
\hline \multicolumn{4}{|l|}{$\mathrm{Nr}$ of previous treatment lines } \\
\hline Median (range) & $3(0-12)$ & $3(0-12)$ & $3(1-7)$ \\
\hline \multicolumn{4}{|l|}{ Toxicity during cycle 1} \\
\hline Any toxicity grade $1-4$ & $51(81)$ & $37(77)$ & $28(93)$ \\
\hline Any toxicity grade 3 or 4 & $22(35)$ & $15(31)$ & $15(50)$ \\
\hline Neutropenia grade $1-4$ & $34(54)$ & $25(52)$ & $19(63)$ \\
\hline Neutropenia grade 3 or 4 & $18(29)$ & $12(25)$ & $13(43)$ \\
\hline Febrile neutropenia & $1(2)$ & $1(2)$ & $1(3)$ \\
\hline \multicolumn{4}{|l|}{ Clearance day 1 cycle $1\left(\mathrm{~L} /\right.$ hour $\left./ \mathrm{m}^{2}\right), n=47$} \\
\hline Median \pm SD & n.a. & $17.8 \pm 5.8$ & n.a. \\
\hline \multicolumn{4}{|l|}{ Histone $\mathrm{H} 3$ phosphorylation, $n=28, \Delta \%$} \\
\hline Median \pm SD & n.a. & $-92.3 \pm 13.1$ & n.a. \\
\hline \multicolumn{4}{|l|}{ Number of treatment courses } \\
\hline Median (range) & $2(1-31)$ & $2(1-31)$ & $2(1-15)$ \\
\hline
\end{tabular}

$R P 2 D$ Recommended phase 2 dose, ECOG Eastern Cooperative Oncology Group, $S D$ standard deviation, Histone H3 phosphorylation:\% change in number of positive cells by immunohistochemistry for Histone $\mathrm{H} 3$ phosphorylation

${ }^{a}$ One patient included in toxicity analyses, but no PK data available

${ }^{\mathrm{b}}$ Fifteen patients of the phase I trial were treated at the RP2D level

Pharmacokinetic, toxicity and biomarker parameters

Pharmacokinetic (PK) evaluation was performed by collecting blood samples on days 1 to 4 , day 8 , days 15 to 18 and day 22 of cycle 1 , and days 1 and 15 of cycles 2 and 4. Pharmacokinetic evaluation was carried out using a non-compartmental approach with the aid of WinNonlin software (version 3.1, Pharsight Inc., Mountain View, CA, USA). In this study, danusertib clearance $\left(\mathrm{L} / \mathrm{hour} / \mathrm{m}^{2}\right)$ was selected as the pharmacokinetic parameter to associate with enzyme and transporter genetic polymorphisms. As mentioned in the phase I report, clearance was not influenced by duration of infusion and was comparable in both 3-hour and 6-hour infusion schedules; 16.2 and 
$18.0 \mathrm{~L} / \mathrm{hour} / \mathrm{m}^{2}$ respectively [20]. Clearances in our study were also comparable to mean danusertib clearance reported in another phase I study using even a 24-hour infusion schedule [8]. Therefore, patients treated at both 3-hour and 6-hour infusion schedules were included in the pharmacokinetic association analyses.

The most frequent and clinically relevant danusertib induced side effects, known from phase I trials, are grade 3 and 4 neutropenia, defined as neutrophil counts $0.5-1.0 * 10^{9} / \mathrm{L}$ and $<0.5 * 10^{9} / \mathrm{L}$, respectively, and febrile neutropenia. These side-effects were therefore considered to be the best candidate toxicity parameters for the association analyses with drug target receptor genetic polymorphisms.

For the association analysis with neutropenia, we included patients treated at the RP2D (thus, $330 \mathrm{mg} / \mathrm{m}^{2}$ days $1,8,15 \mathrm{q} 4 \mathrm{w}$ or $500 \mathrm{mg} / \mathrm{m}^{2}$ days 1 and $15 \mathrm{q} 4 \mathrm{w}$ equivalent). Since grade 3-4 neutropenia was associated with danusertib dose, association analyses were performed with neutropenia developing in the first cycle only, excluding the effects of cumulative danusertib dose and dose reductions in subsequent cycles [21]. The probability of grade 3 or 4 neutropenia in the first danusertib cycle was not influenced by infusion duration and this toxicity was also comparable in both used schedules [8, 22]. Therefore, for the purpose of analyzing associations between drug target receptor polymorphisms and neutropenia all patients treated at the RP2D were combined. Only one case of febrile neutropenia was observed, and as a result association analyses with febrile neutropenia could not be performed.

Skin biopsies for biomarker analysis (Group A) were performed at baseline, and $10 \mathrm{~min}$ before the end of the first infusion in the first cycle. As a biomarker for aurora-B inhibition, the inhibition of histone $\mathrm{H} 3$ phosphorylation in the skin was measured by immunohistochemistry [23-25]. Change in histone $\mathrm{H} 3$ phosphorylation was used as parameter for association analyses with polymorphisms in the aurora-B receptor.

\section{Selection of candidate genes}

Candidate genes were selected based on the information of preclinical pharmacology studies as reported in the Investigator's brochure (Nerviano Medical Sciences on file). Briefly, histone $\mathrm{H} 3$ is phosphorylated by aurora-B and phosphorylation of histone $\mathrm{H} 3$ is inhibited in a number of different tissues (skin, bone marrow, and tumor) after treatment with danusertib. As a consequence, the extent of histone $\mathrm{H} 3$ phosphorylation is studied as a biomarker for danusertib effectiveness. The major route of metabolism of danusertib involves the formation of the $\mathrm{N}$-oxide of the $\mathrm{N}$-methyl piperazine moiety, mainly through the enzyme FMO3. Furthermore, PHA-739358 was found to be a substrate for efflux proteins $\mathrm{ABCG} 2$ and $\mathrm{ABCB} 1$ in in vitro studies [26]. Therefore, for association with clearance $A B C B 1, A B C G 2$, and $F M O 3$ were the genes selected.

Danusertib selectively inhibits the ATP site of aurora-A $\left(\mathrm{IC}_{50}=13 \mathrm{nM}\right)$, aurora-B $\left(\mathrm{IC}_{50}=79 \mathrm{nM}\right)$ and aurora-C $\left(\mathrm{IC}_{50}=61 \mathrm{nM}\right)$ kinases. Tested in a panel of 32 kinases, PHA-739358 also showed increased affinity for other kinases, including $C-A B L, N T R K 1, R E T, F G F R 1, L C K$, FLT4, C-KIT, KDR, CDK2A, STLK1, and FLT. Therefore, inhibition of these kinases may add to danusertib efficacy or toxicity in cancer patients [27, 28]. For correlation with danusertib toxicity selected genes were the drug target genes encoding AURKA, AURKB, AURKC, $C-A B L$, NTRK1, RET, FGFR1, LCK, FLT4, C-KIT, KDR, CDK2A, STLK1, and FLT3.

The single nucleotide polymorphisms (SNPs) were selected, taking into consideration one or more of the following criteria: a validated SNP assay, SNP should preferably cause non-synonymous amino acid changes, an indication for clinical relevance should be available from previous publications, and the preferred minority genotype allele-frequency should be at least $\sim 10 \%$ in Caucasians. For ABCB1, ABCG2, FMO3, AURKA, AURKB, RET, FLT4, $K D R$, and FLT3, one or multiple SNPs could be selected according to these criteria.

DNA extraction, SNP analysis, and haploblock selection

DNA was isolated from EDTA-blood samples with MagNA Pure Compact DNA Isolation kit (Roche Diagnostics, Almere, The Netherlands). DNA concentrations were quantified on the nanodrop (Isogen, IJsselstein, The Netherlands). From the patients of whom whole blood samples were unavailable, DNA was isolated from bloodserum with MagNA Pure Compact DNA Isolation kit. Taqman assays were obtained from Applied Biosystems (Applied Biosystems, Nieuwerkerk aan den IJssel, The Netherlands). SNP genotyping was performed with the BIOMARK 48.48 dynamic array (Fluidigm Corporation, South San Francisco, CA, USA). All assays were performed according to protocols provided by the manufacturer. As a quality control, 4 samples were genotyped in duplicate for all assays and 2 assays were tested in duplicate on all samples. As negative controls water was used. Overall, no inconsistencies in genotypes were observed. To genotype DNA extracted from blood serum on the Biomark, a pre-amplification step was necessary. Briefly, to $1.25 \mu \mathrm{l}$ of serum-DNA a dilution of all taqman assays in a total volume of $1.25 \mu \mathrm{l}$ and $2.5 \mu \mathrm{l}$ of pre-amplification mastermix (Applied Biosystems) was added, and amplified on a conventional PCR machine. This mixture was $20 \times$ diluted and $2.5 \mu \mathrm{l}$ was used in the Biomark conform their protocol. 
Genotype distributions are presented in Table 2. The success rates for all genotyping analyses were $100 \%$, except for $\mathrm{RET} 135 \mathrm{G}>\mathrm{A}$ with $22 \%$ invalid results, despite repeated analyses. Genotype frequencies for 21 of 22 SNPs were in Hardy-Weinberg equilibrium $(P>0.05)$. KDR 1719A $>$ T (rs1870377) was not in Hardy-Weinberg equilibrium which was most likely due to the limited population size. Our genotype frequencies were in line with previously reports and frequencies for Caucasians, as reported in the NCBI database (www.ncbi.nlm.nih.gov).

If linkage disequilibrium between SNPs was detected, haplotypes were set with gPLINK (http://pngu.mgh. harvard.edu/purcell/plink/) [29]. No phase uncertainty in the defined haploblocks and haplotypes $\left(\mathrm{Rh}^{\wedge} 2>0.98\right)$ was seen. The haploblock for $A B C B 1$ included $1236 \mathrm{C}>\mathrm{T}$, $2677 \mathrm{G}>\mathrm{A} / \mathrm{T}$, and $3435 \mathrm{C}>\mathrm{T}$; the haploblock for $A B C G 2$ included $15994 \mathrm{G}>\mathrm{A}$, and $1143 \mathrm{C}>\mathrm{T}$; and the haploblock for FMO3 included $15167 \mathrm{G}>\mathrm{A}, 21443 \mathrm{~A}>\mathrm{G}$, and $18281 \mathrm{G}>\mathrm{A}$ (Table 4).

Statistical analysis

Differences in pharmacokinetic and pharmacodynamic parameters among genotypes were analyzed by the

Table 2 Genotype frequency results

\begin{tabular}{llll}
\hline Gene and Variant & No. Patients & $\mathrm{p}^{\mathrm{a}}$ & $\mathrm{q}^{\mathrm{b}}$ \\
\hline ABCB1 1236C $>$ T & 63 & 0.556 & 0.444 \\
ABCB1 2677G $>$ A $/ \mathrm{T}$ & 63 & 0.563 & 0.437 \\
ABCB1 3435C $>$ T & 63 & 0.484 & 0.516 \\
ABCG2 421C $>$ A & 63 & 0.889 & 0.111 \\
ABCG2 346G $>$ A & 63 & 0.952 & 0.048 \\
ABCG2 1143C $>$ T & 63 & 0.770 & 0.230 \\
ABCG2 15994G $>$ A & 63 & 0.690 & 0.310 \\
FMO3 15167G $>$ A & 63 & 0.563 & 0.437 \\
FMO3 21443A $>$ G & 63 & 0.794 & 0.206 \\
FMO3 18281G $>$ A & 63 & 0.873 & 0.127 \\
KDR-604T $>$ C & 63 & 0.508 & 0.492 \\
KDR 1192G $>$ A & 63 & 0.921 & 0.079 \\
KDR 1719A $>$ T & 63 & 0.254 & 0.746 \\
KDR 54G $>$ A & 63 & 0.563 & 0.437 \\
KDR-92G $>$ A & 63 & 0.762 & 0.238 \\
RET 37412G $>$ A & 63 & 0.810 & 0.190 \\
RET 135G $>$ A & 49 & 0.776 & 0.224 \\
FLT3 738C $>$ T & 63 & 0.397 & 0.603 \\
FLT4 1480A $>$ G & 63 & 0.881 & 0.119 \\
AURKB 893G $>$ A & 63 & 0.889 & 0.111 \\
AURKA 169G $>$ A & 63 & 0.778 & 0.222 \\
AURKA 91A $>$ T & 63 & 0.778 & 0.222 \\
\hline
\end{tabular}

${ }^{\mathrm{a}} p$ frequency of wild-type allele, ${ }^{\mathrm{b}} q$ frequency of variant allele
Student's $t$-test, or analysis of variance (ANOVA) for continuous variables or chi-square test for dichotomous variables, where appropriate. For toxicity, differences in genotype distribution were tested by $3 \times 2$ cross-tabulations for each genotype, and by $2 \times 2$ cross-tabulations for carriers versus noncarriers, with analysis by a two-sided chi-square test. Polymorphisms within a gene were tested with the chi-square test $(\mathrm{P}$-value $<0.05)$ to detect linkage disequilibrium. Associations between the number of copies of a haplotype and clinical parameters were performed using a chi-square test for dichotomous variables and Student's $t$-test, ANOVA for continuous variables.

All statistical analyses were performed using SPSS 16.0 software (SPSS, Chicago, IL) and were two-sided, with a level of significance of $\alpha=0.05$. Because of the explorative nature of this study, we did not perform a correction for multiple comparisons.

\section{Results}

Baseline patient characteristics, observed treatment-related toxicities, pharmacokinetics and treatment duration are presented in Table 1. For associations with clearance, 48 cancer patients treated in the phase I study were analyzed for $A B C B 1, A B C G 2$ and FMO3 polymorphisms. In total, 30 patients at the RP2D were evaluable for pharmacogenetic analyses to compare with toxicity. Our population comprised 98\% Caucasians with 68\% males and 32\% females. Most frequent tumor types were colorectal cancer $(30 \%)$, prostate cancer $(13 \%)$ and breast cancer $(10 \%)$. Danusertib doses used ranged from $45 \mathrm{mg} / \mathrm{m}^{2}$ to $500 \mathrm{mg} / \mathrm{m}^{2}$, with infusion times of $3(14 \%), 6(70 \%)$ and $24 \mathrm{~h}(16 \%)$, according to the designs of the mentioned phase $\mathrm{I}$ and phase II trials.

Haplotype frequencies for $A B C B 1$ were GCC 0.443, TTT 0.412, GTC 0.096, and GCT 0.024, for $A B C G 2 \mathrm{CC}$ 0.691, TT 0.230, and TC 0.079, and for FMO3 AGA 0.437, GGG 0.437, and GAG 0.127. Haploblock for $K D R$ included-604 $\mathrm{T}>\mathrm{C}, 1192 \mathrm{G}>\mathrm{A}$, and $1719 \mathrm{~A}>\mathrm{T}$, for $R E T$ $37412 \mathrm{G}>\mathrm{A}$, and $135 \mathrm{G}>\mathrm{A}$, and for $A U R K A 169 \mathrm{G}>\mathrm{A}$, and $91 \mathrm{~A}>\mathrm{T}$. Haplotype frequencies for $K D R$ were TCT 0.410 , CCT 0.316, CCA 0.109, TCA 0.087, CTA 0.047, CTT 0.021, and TTA 0.0114, for RET GG 0.602, and GA 0.938, and for AURKA GA 0.556, AA 0.222, and GT 0.222.

There was no apparent association between cycle 1 day 1 danusertib clearance $\left(\mathrm{L} /\right.$ hour $\left./ \mathrm{m}^{2}\right)$ and genetic polymorphisms in $A B C B 1$ or $A B C G 2$ (Table 3). However, for FMO3, patients carrying at least one $\mathrm{G}$ allele had a significantly slower clearance compared to the 18281 AA patients $(P=0.017)$.

No relationship between observed grade 3-4 neutropenia in the first treatment cycle and KDR, RET, FLT3, FLT4, 
Table 3 Association between genetic polymorphisms and danusertib clearance

\begin{tabular}{|c|c|c|c|c|c|}
\hline \multirow[t]{2}{*}{ Gene } & \multirow[t]{2}{*}{ Polymorphism } & \multirow[t]{2}{*}{ Genotype } & \multirow[t]{2}{*}{ No. Patients } & \multicolumn{2}{|c|}{ Clearance $\mathrm{L} /$ hour $/ \mathrm{m}^{2} \mathrm{~d} 1 \mathrm{c} 1$} \\
\hline & & & & Mean & $\mathrm{SD}$ \\
\hline \multirow[t]{12}{*}{$A B C B 1$} & \multirow[t]{4}{*}{$1236 \mathrm{C}>\mathrm{T}$} & $\mathrm{CC}$ & 16 & 17.8 & 6.5 \\
\hline & & $\mathrm{CT}$ & 21 & 18.3 & 5.9 \\
\hline & & $\mathrm{TT}$ & 10 & 18.6 & 4.9 \\
\hline & & P-value & & 0.930 & \\
\hline & $2677 \mathrm{G}>\mathrm{A} / \mathrm{T}$ & GG & 17 & 18.2 & 6.6 \\
\hline & \multirow[t]{3}{*}{ GT } & 20 & 18.5 & 5.8 & \\
\hline & & $\mathrm{TT}$ & 10 & 17.7 & 4.9 \\
\hline & & P-value & & 0.948 & \\
\hline & \multirow[t]{4}{*}{$3435 \mathrm{C}>\mathrm{T}$} & $\mathrm{CC}$ & 13 & 19.5 & 6.1 \\
\hline & & $\mathrm{CT}$ & 21 & 17.7 & 5.9 \\
\hline & & $\mathrm{TT}$ & 13 & 17.8 & 5.6 \\
\hline & & P-value & & 0.638 & \\
\hline \multirow[t]{14}{*}{$A B C G 2$} & \multirow[t]{3}{*}{$421 \mathrm{C}>\mathrm{A}$} & $\mathrm{CC}$ & 36 & 18.1 & 6.1 \\
\hline & & $\mathrm{CA}$ & 11 & 18.8 & 4.8 \\
\hline & & P-value & & 0.621 & \\
\hline & \multirow[t]{3}{*}{$346 \mathrm{G}>\mathrm{A}$} & GG & 45 & 18.2 & 5.9 \\
\hline & & GA & 2 & 18.6 & 5.2 \\
\hline & & P-value & & 0.755 & \\
\hline & \multirow[t]{4}{*}{$143 \mathrm{C}>\mathrm{T}$} & $\mathrm{CC}$ & 29 & 18.9 & 6.1 \\
\hline & & $\mathrm{CT}$ & 15 & 17.3 & 5.5 \\
\hline & & $\mathrm{TT}$ & 3 & 16. & 3.6 \\
\hline & & P-value & & 0.537 & \\
\hline & $15994 \mathrm{G}>\mathrm{A}$ & GG & 23 & 18.5 & 5.0 \\
\hline & \multirow[t]{3}{*}{ GA } & 21 & 18.2 & 6.2 & \\
\hline & & $\mathrm{AA}$ & 3 & 16.5 & 3.6 \\
\hline & & P-value & & 0.859 & \\
\hline \multirow[t]{12}{*}{ FMO3 } & \multirow[t]{4}{*}{$15167 \mathrm{G}>\mathrm{A}$} & GG & 15 & 19.5 & 6.6 \\
\hline & & GA & 20 & 18.1 & 6.0 \\
\hline & & $\mathrm{AA}$ & 12 & 16.9 & 4.2 \\
\hline & & P-value & & 0.537 & \\
\hline & \multirow[t]{4}{*}{$21443 A>G$} & $\mathrm{AA}$ & 27 & 19.2 & 6.3 \\
\hline & & $\mathrm{AG}$ & 18 & 16.9 & 5.1 \\
\hline & & GG & 2 & 16.4 & 1.3 \\
\hline & & P-value & & 0.382 & \\
\hline & \multirow[t]{4}{*}{$18281 \mathrm{G}>\mathrm{A}$} & GG & 35 & 18.1 & 5.2 \\
\hline & & GA & 11 & 17.2 & 6.1 \\
\hline & & $\mathrm{AA}$ & 1 & 34.0 & n.a. \\
\hline & & P-value & & 0.017 & \\
\hline
\end{tabular}

n.a: not applicable

$A U R K B$ or $A U R K A$ genotype was observed (Table 4). Also the $A B C B 1, A B C G 2$, and $F M O 3$ haplotypes did not show an association with danusertib clearance, nor did $K D R$, RET, AURKA haplotypes relate to danusertib induced grade 3-4 neutropenia (Table 5).

Also, no association was observed between the studied AURKB polymorphism and change in level of histone $\mathrm{H} 3$ phosphorylation induced by danusertib. The decrease in histone $\mathrm{H} 3$ phosphorylation for AURKB homozygous wild type genotypes (GG) was 91\% (SD 13.3\%), while the heterozygous genotype (GA) had a decrease of $84 \%$ (SD $12.2 \%, P=0.223)$.

\section{Discussion}

Aurora kinase inhibitors are relatively new and promising agents in development for anticancer treatment [1-9]. The 
Table 4 Association between genetic polymorphisms and grade 3-4 neutropenia in cycle 1 in all patients at RP2D levels

\begin{tabular}{|c|c|c|c|c|c|c|}
\hline \multicolumn{6}{|c|}{ Neutropenia grade $3-4$} & \multirow{2}{*}{$\begin{array}{l}p \text {-value } \\
\text { wt/wt vs wt } / \mathrm{m} \text { vs } \mathrm{m} / \mathrm{m}\end{array}$} \\
\hline Gene & Polymorphism & Genotype & Total No. Patients & No & Yes & \\
\hline \multirow[t]{14}{*}{$K D R$} & \multirow[t]{3}{*}{$-604 \mathrm{~T}>\mathrm{C}$} & TT & 6 & 3 & 3 & \multirow[t]{3}{*}{0.308} \\
\hline & & $\mathrm{TC}$ & 15 & 7 & 8 & \\
\hline & & $\mathrm{CC}$ & 9 & 7 & 2 & \\
\hline & \multirow[t]{2}{*}{$1192 \mathrm{G}>\mathrm{A}$} & GG & 27 & 15 & 12 & \multirow[t]{2}{*}{1.000} \\
\hline & & GA & 3 & 2 & 1 & \\
\hline & \multirow[t]{3}{*}{$1719 \mathrm{~A}>\mathrm{T}$} & $\mathrm{AA}$ & 1 & 0 & 1 & \multirow[t]{3}{*}{0.426} \\
\hline & & AT & 15 & 8 & 7 & \\
\hline & & TT & 14 & 9 & 5 & \\
\hline & \multirow[t]{3}{*}{$54 \mathrm{G}>\mathrm{A}$} & GG & 9 & 5 & 4 & \multirow[t]{3}{*}{0.673} \\
\hline & & GA & 16 & 10 & 6 & \\
\hline & & $\mathrm{AA}$ & 5 & 2 & 3 & \\
\hline & \multirow[t]{3}{*}{$-92 \mathrm{G}>\mathrm{A}$} & $\mathrm{AA}$ & 3 & 3 & 0 & \multirow[t]{3}{*}{0.265} \\
\hline & & $\mathrm{AG}$ & 7 & 4 & 3 & \\
\hline & & GG & 20 & 10 & 10 & \\
\hline \multirow[t]{6}{*}{$R E T$} & \multirow[t]{3}{*}{$37412 \mathrm{G}>\mathrm{A}$} & GG & 24 & 14 & 10 & \multirow[t]{3}{*}{0.507} \\
\hline & & GA & 5 & 2 & 3 & \\
\hline & & $\mathrm{AA}$ & 1 & 1 & 0 & \\
\hline & $135 \mathrm{G}>\mathrm{A}$ & GG & 16 & 9 & 7 & \multirow[t]{3}{*}{0.489} \\
\hline & \multirow[t]{2}{*}{3 missing } & GA & 8 & 6 & 2 & \\
\hline & & $\mathrm{AA}$ & 3 & 1 & 2 & \\
\hline \multirow[t]{3}{*}{ FLT3 } & \multirow[t]{3}{*}{$738 \mathrm{C}>\mathrm{T}$} & $\mathrm{CC}$ & 5 & 4 & 1 & \multirow[t]{3}{*}{0.414} \\
\hline & & $\mathrm{CT}$ & 15 & 7 & 8 & \\
\hline & & $\mathrm{TT}$ & 10 & 6 & 4 & \\
\hline \multirow[t]{2}{*}{ FLT4 } & \multirow[t]{2}{*}{$1480 \mathrm{~A}>\mathrm{G}$} & $\mathrm{AA}$ & 23 & 12 & 11 & \\
\hline & & $\mathrm{AG}$ & 7 & 5 & 2 & \\
\hline \multirow[t]{2}{*}{$A U R K B$} & \multirow[t]{2}{*}{$893 \mathrm{G}>\mathrm{A}$} & GG & 22 & 11 & 11 & \multirow[t]{2}{*}{0.407} \\
\hline & & GA & 8 & 6 & 2 & \\
\hline \multirow[t]{6}{*}{$A U R K A$} & \multirow[t]{3}{*}{$169 \mathrm{G}>\mathrm{A}$} & GG & 18 & 10 & 8 & 0.672 \\
\hline & & GA & 11 & 6 & 5 & \\
\hline & & $\mathrm{AA}$ & 1 & 1 & 0 & \\
\hline & $91 \mathrm{~A}>\mathrm{T}$ & $\mathrm{AA}$ & 20 & 11 & 9 & 0.110 \\
\hline & & $\mathrm{AT}$ & 6 & 2 & 4 & \\
\hline & & TT & 4 & 4 & 0 & \\
\hline
\end{tabular}

current knowledge on treatment actions, toxicity, biomarkers and efficacy is still very limited. Danusertib is the first aurora kinase inhibitor in which a pharmacogenetic pathway analysis has been performed to clarify pharmacokinetic and pharmacodynamic features of the drug.

In the last decade, well known examples of anti-cancer drugs can be given, for which initial recommended doselevels had to be changed based on toxicity in subgroups of patients [30-33]. These subgroups of patients, with in general decreased enzymatic function based on genetic polymorphisms, could have been identified earlier if pharmacogenetic knowledge was available at an earlier stage. Therefore, it is recognized more and more that pharmacogenetic research in the earliest stages of development of new anti-cancer agents is highly relevant. While the basic characteristics of the new agent have to become more clear, also selection of patients with potential increased toxicity, or decreased efficacy, should be performed as early as possible. Therefore, the decision was made not to delay the pharmacogenetic analyses till after registration of the compound, but to explore potentially clinical relevant pharmacogenetic variation at this stage of development.

Our study was conducted in patients of a recent phase I trial and subsets of two phase II trials of danusertib, and therefore patient numbers for both pharmacokinetic and 
Table 5 Haplotype analysis: uncorrected $\mathrm{P}$ values using Pearson $X^{2}$ analysis, independent samples t-test or one-way ANOVA where appropriate

\begin{tabular}{|c|c|c|c|}
\hline Gene & SNPS & Haplotype & Neutropenia grade 3-4 p-value \\
\hline \multirow[t]{3}{*}{ KDR } & $-604 \mathrm{~T}>\mathrm{C}$ & TCT & 0.146 \\
\hline & $1192 \mathrm{G}>\mathrm{A}$ & $\mathrm{CCT}$ & 0.460 \\
\hline & $1719 \mathrm{~A}>\mathrm{T}$ & CCA & 1.000 \\
\hline \multirow[t]{2}{*}{ RET } & $37412 \mathrm{G}>\mathrm{A}$ & GG & 0.773 \\
\hline & $135 \mathrm{G}>\mathrm{A}$ & GA & 0.773 \\
\hline \multirow[t]{3}{*}{ AURKA } & $169 \mathrm{G}>\mathrm{A}$ & GA & 0.205 \\
\hline & $91 \mathrm{~A}>\mathrm{T}$ & AA & 0.672 \\
\hline & & GT & 0.110 \\
\hline Gene & SNPS & Haplotype & $\mathrm{p}$-value clearance $\mathrm{L} /$ hour $/ \mathrm{m}^{2} \mathrm{~d} 1 \mathrm{c} 1$ \\
\hline \multirow[t]{3}{*}{$\mathrm{ABCB} 1$} & $1236 \mathrm{C}>\mathrm{T}$ & GCC & 0.953 \\
\hline & $2677 \mathrm{G}>\mathrm{A} / \mathrm{T}$ & TTT & 0.935 \\
\hline & $3435 \mathrm{C}>\mathrm{T}$ & & \\
\hline \multirow[t]{2}{*}{ ABCG2 } & $15994 \mathrm{G}>\mathrm{A}$ & $\mathrm{CC}$ & 0.859 \\
\hline & $1143 \mathrm{C}>\mathrm{T}$ & TT & 0.588 \\
\hline \multirow[t]{3}{*}{ FMO3 } & $15167 \mathrm{G}>\mathrm{A}$ & AGA & 0.537 \\
\hline & $21443 \mathrm{~A}>\mathrm{G}$ & GGG & 0.603 \\
\hline & $18281 \mathrm{G}>\mathrm{A}$ & GAC & 0.017 \\
\hline
\end{tabular}

pharmacodynamic association analyses are relatively limited. However, in the phase I trial DNA-data were available for almost the entire patient population, making selection bias less likely. The two phase II trials are still ongoing and blood for DNA analysis was available for all patients included in the trials at the Erasmus University Medical Center at the moment of pharmacogenetic analyses.

A correlation between danusertib pharmacokinetics and pharmacogenetic variation is only seen for the FMO3 $18281 \mathrm{G}>\mathrm{A}$ homozygous variant and clearance. However, this is based on a single patient for whom clearance was markedly elevated. Therefore, the relevance of this finding is unclear. For the other 2 SNPs (15167 G $>$ A and $21443 \mathrm{G}>\mathrm{A}$ ) in this gene, a pattern to altered clearance, based on genotype, is suggested. As FMO3 is responsible for the main route of metabolism of danusertib, this warrants further research.

Currently, the mechanism causing neutropenia after danusertib treatment is unclear and could be associated with peak values $\left(\mathrm{C}_{\max }\right)$ or threshold values. Based on the new pharmacogenetic data from our current analysis no predisposition for the severity of haematological toxicity could be identified.

Clearly, this study has its limitations. As described earlier, due to the phase I and II nature of the studies patient numbers were limited and the group is quite heterogeneous. The power to find statistical significant differences in genotype of haplotype analyses was limited.

That clear correlations between the main enzymes and transporters involved in danusertib metabolism, and pharmacokinetics and toxicity are absent, does not mean that these results are unimportant. This study outcome makes the chance that danusertib is highly susceptible to pharmacogenetic variation less probable. More discrete differences, based on pharmacogenetic variability, should be explored further in additional (population based) pharmacogenetic studies for this compound [34-36]. The relatively high inter-individual variation observed could not be explained through pharmacogenetics and, for instance, the role of environmental factors might be important.

The reason for a lack of association between histone $\mathrm{H} 3$ phosphorylation and the studied AURKB polymorphism is unclear. Whether the $893 \mathrm{G}>\mathrm{A}$ mutation results in altered gene function is unknown.

Since danusertib is currently used in two treatment schedules, $330 \mathrm{mg} / \mathrm{m}^{2}$ on days 1,8 and 15 every 4 weeks and $500 \mathrm{mg} / \mathrm{m}^{2}$ on days 1 and 15 every 4 weeks, a population based pharmacokinetic-pharmacogenetic model might help in selecting the optimal treatment schedule [36-38]. A second advantage of a population based pharmacokineticpharmacogenetic model is that the relative impact of all individual SNPs as covariates can be explored.

In conclusion, in this explorative study no significant associations between polymorphisms in genes coding for drug metabolizing enzyme, for transporter proteins and clearance of danusertib, between target receptor polymorphisms and toxicity of danusertib and between polymorphisms in the aurora kinase $\mathrm{B}$ receptor and the extent of histone $\mathrm{H} 3$ phosphorylation were seen. Future studies, including analyses of more patients on danusertib treatment and the use of population based pharmacokinetic-pharmacogenetic models to select the optimal danusertib treatment schedule are planned. 
Acknowledgements We would like to acknowledge the contribution of Vincent Dezentje (Departments of Medical Oncology and Clinical Pharmacy and Toxicology LUMC) in anonymizing all data, Margret den Hollander and Jan Ouwerkerk (Department of Medical Oncology LUMC) for data and sample collection, Renee Baak-Pablo (Department of Clinical Pharmacy and Toxicology LUMC) for SNP analysis, and Ronald de Wit (Department of Medical Oncology EUMC) as principal investigator in the phase II prostate study.

\section{Funding None}

Conflicts of interest statement Three authors (MM, BL, SC) are affiliated to Nerviano Medical Sciences. There are no actual or potential conflicts of interests, influencing judgement on the part of the other author.

Open Access This article is distributed under the terms of the Creative Commons Attribution Noncommercial License which permits any noncommercial use, distribution, and reproduction in any medium, provided the original author(s) and source are credited.

\section{References}

1. Jones SF, Cohen RB, Dees EC, Lee Y, Papas JA, Cooper MR et al. (2007). Phase I clinical trial of MLN8054, a selective inhibitor of Aurora A kinase. J Clin Oncol 25:18s (suppl; abstr 3577)

2. Renshaw S, Patnaik A, Gordon M, Beeram M, Fischer D, Gianella-Borradori A et al. (2007). A phase I two arm trial of AS703569 (R763), an orally available aurora kinase inhibitor, in subjects with solid tumors: preliminary results. J Clin Oncol 25:18s (suppl; abstr 14130)

3. Rubin EH, Shapiro GI, Stein MN, Watson P, Bergstrom D, Xiao A et al. (2006) A phase I clinical and pharmacokinetic (PK) trial of the aurora kinase (AK) inhibitor MK-0457 in cancer patients. J Clin Oncol 24:18s (suppl; abstr 3009).

4. Schellens JH, Boss D, Witteveen PO, Zandvliet A, Beijnen JH, Voogel-Fuchs $\mathrm{M}$ et al. (2006). Phase I and pharmacological study of the novel aurora kinase inhibitor AZD1152. J Clin Oncol 24:18s (suppl; abstr 3008).

5. Foran JM, Ravandi F, O'Brien SM, Borthakur G, Rios M, Boone $P$ et al. (2008). Phase I and pharmacodynamic trial of AT9283, an aurora kinase inhibitor, in patients with refractory leukemia. J Clin Oncol 26:18s (suppl; abstr 2518).

6. Jones SF, Burris HA, Dumez H, Infante JR, Fowst C, Gerletti P et al. (2008). Phase I accelerated dose-escalation, pharmacokinetic (PK) and pharmacodynamic study of PF-03814735, an oral aurora kinase inhibitor, in patients with advanced solid tumors: Preliminary results. J Clin Oncol 26:18s (suppl; abstr 2517)

7. Robert F, Hurwitz H, Verschraegen CF, Advani R, Berman C, Taverna $\mathrm{P}$ et al. (2008). Phase 1 trial of SNS-314, a novel selective inhibitor of aurora kinases $\mathrm{A}, \mathrm{B}$, and $\mathrm{C}$, in advanced solid tumor patients. J Clin Oncol 26:18s (suppl; abstr 14642).

8. Cohen RB, Jones SF, von Mehren M, Cheng J, Spiegel DM, Laffranchi B et al. (2008). Phase I study of the pan aurora kinases (AKs) inhibitor PHA-739358 administered as a $24 \mathrm{~h}$ infusion without/with G-CSF in a 14-day cycle in patients with advanced solid tumors. J Clin Oncol 26:18s (suppl; abstr 2520).

9. Plummer ER, Calvert H, Arkenau H, Mallett KH, Squires M, Smith D et al. (2008). A dose-escalation and pharmacodynamic study of AT9283 in patients with refractory solid tumours. J Clin Oncol 26:18s (suppl; abstr 2519)
10. Carpinelli P, Ceruti R, Giorgini ML, Cappella P, Gianellini L, Croci V, Degrassi A, Texido G, Rocchetti M, Vianello P, Rusconi L, Storici P, Zugnoni P, Arrigoni C, Soncini C, Alli C, Patton V, Marsiglio A, Ballinari D, Pesenti E, Fancelli D, Moll J (2007) PHA-739358, a potent inhibitor of Aurora kinases with a selective target inhibition profile relevant to cancer. Mol Cancer Ther 6:3158-3168

11. Fancelli D, Moll J, Varasi M, Bravo R, Artico R, Berta D, Bindi S, Cameron A, Candiani I, Cappella P, Carpinelli P, Croci W, Forte B, Giorgini ML, Klapwijk J, Marsiglio A, Pesenti E, Rocchetti M, Roletto F, Severino D, Soncini C, Storici P, Tonani R, Zugnoni P, Vianello P (2006) 1, 4, 5, 6-tetrahydropyrrolo[3, 4-c]pyrazoles: identification of a potent Aurora kinase inhibitor with a favorable antitumor kinase inhibition profile. J Med Chem 49:7247-7251

12. Warner SL, Gray PJ, Von Hoff DD (2006) Tubulin-associated drug targets: Aurora kinases, Polo-like kinases, and others. Semin Oncol 33:436-448

13. Carvajal RD, Tse A, Schwartz GK (2006) Aurora kinases: new targets for cancer therapy. Clin Cancer Res 12:6869-6875

14. Carpinelli P, Ceruti R, Giorgini ML, Cappella P, Gianellini L, Croci V, Degrassi A, Texido G, Rocchetti M, Vianello P, Rusconi L, Storici P, Zugnoni P, Arrigoni C, Soncini C, Alli C, Patton V, Marsiglio A, Ballinari D, Pesenti E, Fancelli D, Moll J (2007) PHA-739358, a potent inhibitor of Aurora kinases with a selective target inhibition profile relevant to cancer. Mol Cancer Ther 6:3158-3168

15. Carpinelli P, Ceruti R, Giorgini ML, Cappella P, Gianellini L, Croci V, Degrassi A, Texido G, Rocchetti M, Vianello P, Rusconi L, Storici P, Zugnoni P, Arrigoni C, Soncini C, Alli C, Patton V, Marsiglio A, Ballinari D, Pesenti E, Fancelli D, Moll J (2007) PHA-739358, a potent inhibitor of Aurora kinases with a selective target inhibition profile relevant to cancer. Mol Cancer Ther 6:3158-3168

16. Steeghs N, Eskens FA, Gelderblom H, Verweij J, Nortier JW, Ouwerkerk J, van Noort C, Mariani M, Spinelli R, Carpinelli P, Laffranchi B, de Jonge MJ (2009) Phase I pharmacokinetic and pharmacodynamic study of the aurora kinase inhibitor danusertib in patients with advanced or metastatic solid tumors. J Clin Oncol 27:5094-5101

17. Steeghs N, Eskens FA, Gelderblom H, Verweij J, Nortier JW, Ouwerkerk J, van Noort C, Mariani M, Spinelli R, Carpinelli P, Laffranchi B, de Jonge MJ (2009) Phase I pharmacokinetic and pharmacodynamic study of the aurora kinase inhibitor danusertib in patients with advanced or metastatic solid tumors. J Clin Oncol 27:5094-5101

18. Steeghs N, Eskens FA, Gelderblom H, Verweij J, Nortier JW, Ouwerkerk J, van Noort C, Mariani M, Spinelli R, Carpinelli P, Laffranchi B, de Jonge MJ (2009) Phase I pharmacokinetic and pharmacodynamic study of the aurora kinase inhibitor danusertib in patients with advanced or metastatic solid tumors. J Clin Oncol 27:5094-5101

19. Therasse P, Arbuck SG, Eisenhauer EA, Wanders J, Kaplan RS, Rubinstein L, Verweij J, Van GM, van Oosterom AT, Christian MC, Gwyther SG (2000) New guidelines to evaluate the response to treatment in solid tumors. European Organization for Research and Treatment of Cancer, National Cancer Institute of the United States, National Cancer Institute of Canada. J Natl Cancer Inst 92:205-216

20. Steeghs N, Eskens FA, Gelderblom H, Verweij J, Nortier JW, Ouwerkerk J, van Noort C, Mariani M, Spinelli R, Carpinelli P, Laffranchi B, de Jonge MJ (2009) Phase I pharmacokinetic and pharmacodynamic study of the aurora kinase inhibitor danusertib in patients with advanced or metastatic solid tumors. J Clin Oncol 27:5094-5101

21. Steeghs N, Eskens FA, Gelderblom H, Verweij J, Nortier JW, Ouwerkerk J, van Noort C, Mariani M, Spinelli R, Carpinelli P, Laffranchi B, de Jonge MJ (2009) Phase I pharmacokinetic and 
pharmacodynamic study of the aurora kinase inhibitor danusertib in patients with advanced or metastatic solid tumors. J Clin Oncol 27:5094-5101

22. Steeghs N, Eskens FA, Gelderblom H, Verweij J, Nortier JW, Ouwerkerk J, van Noort C, Mariani M, Spinelli R, Carpinelli P, Laffranchi B, de Jonge MJ (2009) Phase I pharmacokinetic and pharmacodynamic study of the aurora kinase inhibitor danusertib in patients with advanced or metastatic solid tumors. J Clin Oncol 27:5094-5101

23. Carpinelli P, Ceruti R, Giorgini ML, Cappella P, Gianellini L, Croci V, Degrassi A, Texido G, Rocchetti M, Vianello P, Rusconi L, Storici P, Zugnoni P, Arrigoni C, Soncini C, Alli C, Patton V, Marsiglio A, Ballinari D, Pesenti E, Fancelli D, Moll J (2007) PHA739358, a potent inhibitor of Aurora kinases with a selective target inhibition profile relevant to cancer. Mol Cancer Ther 6:3158-3168

24. Soncini C, Carpinelli P, Gianellini L, Fancelli D, Vianello P, Rusconi L, Storici P, Zugnoni P, Pesenti E, Croci V, Ceruti R, Giorgini ML, Cappella P, Ballinari D, Sola F, Varasi M, Bravo R, Moll J (2006) PHA-680632, a novel Aurora kinase inhibitor with potent antitumoral activity. Clin Cancer Res 12:4080-4089

25. Camidge DR, Pemberton MN, Growcott JW, Johnstone D, Laud PJ, Foster JR, Randall KJ, Hughes AM (2005) Assessing proliferation, cell-cycle arrest and apoptotic end points in human buccal punch biopsies for use as pharmacodynamic biomarkers in drug development. Br J Cancer 93:208-215

26. Carpinelli P, Ceruti R, Giorgini ML, Cappella P, Gianellini L, Croci V, Degrassi A, Texido G, Rocchetti M, Vianello P, Rusconi L, Storici P, Zugnoni P, Arrigoni C, Soncini C, Alli C, Patton V, Marsiglio A, Ballinari D, Pesenti E, Fancelli D, Moll J (2007) PHA-739358, a potent inhibitor of Aurora kinases with a selective target inhibition profile relevant to cancer. Mol Cancer Ther 6:3158-3168

27. Carpinelli P, Ceruti R, Giorgini ML, Cappella P, Gianellini L, Croci V, Degrassi A, Texido G, Rocchetti M, Vianello P, Rusconi L, Storici P, Zugnoni P, Arrigoni C, Soncini C, Alli C, Patton V, Marsiglio A, Ballinari D, Pesenti E, Fancelli D, Moll J (2007) PHA-739358, a potent inhibitor of Aurora kinases with a selective target inhibition profile relevant to cancer. Mol Cancer Ther 6:3158-3168

28. Fancelli D, Moll J, Varasi M, Bravo R, Artico R, Berta D, Bindi S, Cameron A, Candiani I, Cappella P, Carpinelli P, Croci W, Forte B, Giorgini ML, Klapwijk J, Marsiglio A, Pesenti E, Rocchetti M,
Roletto F, Severino D, Soncini C, Storici P, Tonani R, Zugnoni P, Vianello P (2006) 1, 4, 5, 6-tetrahydropyrrolo[3, 4-c]pyrazoles: identification of a potent Aurora kinase inhibitor with a favorable antitumor kinase inhibition profile. J Med Chem 49:7247-7251

29. Purcell S, Neale B, Todd-Brown K, Thomas L, Ferreira MA, Bender D, Maller J, Sklar P, de Bakker PI, Daly MJ, Sham PC (2007) PLINK: a tool set for whole-genome association and population-based linkage analyses. Am J Hum Genet 81:559-575

30. Swen JJ, Huizinga TW, Gelderblom H, de Vries EG, Assendelft WJ, Kirchheiner J, Guchelaar HJ (2007) Translating pharmacogenomics: challenges on the road to the clinic. PLoS Med 4:e209

31. Ridge SA, Sludden J, Wei X, Sapone A, Brown O, Hardy S, Canney P, Fernandez-Salguero P, Gonzalez FJ, Cassidy J, McLeod HL (1998) Dihydropyrimidine dehydrogenase pharmacogenetics in patients with colorectal cancer. Br J Cancer 77:497-500

32. Goetz MP, Kamal A, Ames MM (2008) Tamoxifen pharmacogenomics: the role of CYP2D6 as a predictor of drug response. Clin Pharmacol Ther 83:160-166

33. Iyer L, Das S, Janisch L, Wen M, Ramirez J, Karrison T, Fleming GF, Vokes EE, Schilsky RL, Ratain MJ (2002) UGT1A1*28 polymorphism as a determinant of irinotecan disposition and toxicity. Pharmacogenomics J 2:43-47

34. Zwaveling J, Press RR, Bredius RG, van Derstraaten TR, den HJ B, IH BJJ, Guchelaar HJ (2008) Glutathione S-transferase polymorphisms are not associated with population pharmacokinetic parameters of busulfan in pediatric patients. Ther Drug Monit 30:504-510

35. Mandema JW, Verotta D, Sheiner LB (1992) Building population pharmacokinetic-pharmacodynamic models. I. Models for covariate effects. J Pharmacokinet Biopharm 20:511-528

36. Zandvliet AS, Schellens JH, Beijnen JH, Huitema AD (2008) Population pharmacokinetics and pharmacodynamics for treatment optimization in clinical oncology. Clin Pharmacokinet 47:487-513

37. Zwaveling J, Press RR, Bredius RG, van Derstraaten TR, den HJ B, IH BJJ, Guchelaar HJ (2008) Glutathione S-transferase polymorphisms are not associated with population pharmacokinetic parameters of busulfan in pediatric patients. Ther Drug Monit 30:504-510

38. Mandema JW, Verotta D, Sheiner LB (1992) Building population pharmacokinetic-pharmacodynamic models. I. Models for covariate effects. J Pharmacokinet Biopharm 20:511-528 